\title{
Considerations for African hospitals and care systems of the future in the face of emerging infectious diseases like Ebola
}

\author{
Kenneth Anchang Yongabi ${ }^{1}$, Judith Abit Nota ${ }^{2}$, Gilbert Nota Teko ${ }^{3}$ \\ ${ }^{1}$ Tropical Public health Research Group, Phytobiotechnology Research Foundation Institute (PRF), Catholic University of Cameroon, \\ Bamenda \\ ${ }^{2}$ Counseling Department, Government High School, Bali, Bamenda, Cameroon \\ ${ }^{3}$ Health economics Department, Catholic University of Cameroon, Bamenda
}

Email address:

yongabika@yahoo.com (K. A. Yongabi)

\section{To cite this article:}

Kenneth Anchang Yongabi, Judith Abit Nota, Gilbert Nota Teko. Considerations for African Hospitals and Care Systems of the Future in the Face of Emerging Infectious Diseases Like Ebola. American Journal of Clinical and Experimental Medicine. Special Issue: Clinical Innovations, Developments in the Diagnosis, Management and Prevention of Ebola Disease (Marburg Fever) and Hemorrhagic Fevers. Vol. 3, No. 1-1, 2015, pp. 38-45. doi: 10.11648/j.ajcem.s.2015030101.18

\begin{abstract}
In this paper, we attempt to discuss ideas for a radical shift in health care practice in Africa that underpins the complexity of the African environment. We note that despite increasing financial support in the control of infectious diseases in Africa, the endemicity and emergence of new diseases are still unabated. Taking lessons from the current Ebola outbreak, treatment and maximum containment, African medics require a re-training and reorganization professionally to abate future epidemics. We noted that innovative clinical techniques in intensive health care, diagnosis, clinical counseling, and treatment as well as prevention are critical elements to build on for effective management of Ebola. We also provide suggestions for a culture driven health care infrastructure in the predictions and management of future outbreaks of diseases such as Ebola. Future directions on hospital wastewater treatment in health care centers using small scale anaerobic digesters and the use of traditional phytodisinfectants as low cost strategies to reduce dissemination of pathogens onto the environment are discussed.
\end{abstract}

Keywords: Ebola Virus, Emerging Infectious Diseases, African Hospitals, Health Care, Systems, Counseling, Integrated

\section{Introduction}

Approximately seventy to eighty percent of Africans live in rural areas and practice subsistent fragmented agriculture including hunting. Poverty, disease and environmental degradation are an increasing phenomenon across Africa. This has led to declining health status, and so most Africans play host to many diseases such as malaria, typhoid, and skin diseases. These diseases have remained endemic.

Due to the high cost of drugs and inaccessibility to urban areas to purchase drugs when money is available, they generally, resort to exploiting local knowledge, visit traditional medicine doctors, self medication and or visit defacto doctors or just abandon themselves to the fate. Infectious diseases remain a security challenge - the dreaded Fourth Horseman of the Apocalypse. Historically, Plague of Athens heralded end of Greece' Golden Age. In 1300s Black Death in Europe killed $40 \%$ of the population while in 1500 s smallpox in Latin America killed 10-15 million. In 1918 Influenza pandemic during World War 1, took 20-40 million lives. The wars continue today. Twenty well-known maladies such as Tuberculosis, malaria, cholera and influenza have reemerged and are spreading. At least 30 diseases with strains not previously known such as Ebola, hepatitis C, Hantavirus, Severe Acquired Respiratory Syndrome (SARS) and HIV have emerged.

All the wars of the 20th century killed an average of about 1.1 million combatants and civilians yearly but communicable diseases are now killing 14 times as many people annually. Diseases rank with wars and famine as major security threats. Diseases are a leading cause of death and disability worldwide. Infectious diseases have been called pestilences, pests and plagues since ancient times the emergence of new infectious diseases, a resurgence of older diseases, a spread of resistance to a growing number of old and new antibiotics. The campaign to eradicate infectious 
disease is ongoing; pathogens are exhibiting remarkable resilience and flexibility.

The whole world is threatened by emerging infectious diseases, but the regional responses to such threats vary considerably. Africa, certainly, would be the least in terms of medical preparedness to deal with future epidemics. For instance, the HIV/AIDs pandemic has probably killed and devastated more Africans than any other continent in the world. One could argue that the toll of infections have more impact negatively on less developed countries as a whole. However, amongst the less developed countries, Africa is still least on response level with respect to the infrastructure and political will. Let us take the case of Fig.1 below, when the human avian flu stroke from Asia, the response was better and containment better than it would have been in Africa.

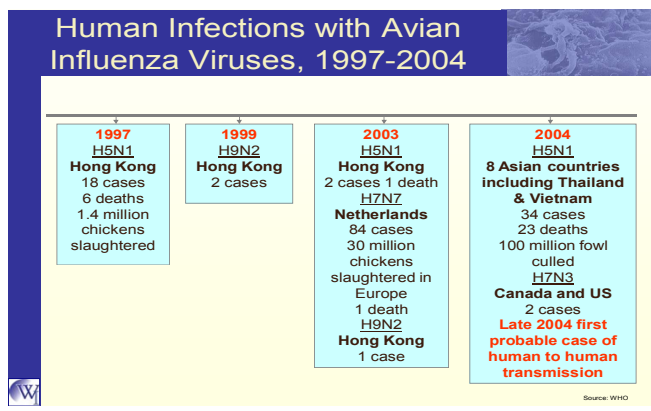

Fig. 1. Human Infections with avian Influenza Viruses from 1997-2004

\section{Why are Infectious Diseases Emerging and Persisting in Africa}

This seemly is a question looking simple to answer but it may be very difficult to have a simple answer. The World Health Organization (WHO) spends a quarter of its budget in the control of infectious diseases in Africa, yet infectious diseases continue to emerge and more so difficult to eliminate and or control effectively (Table 1, below)

More than 10 years ago; the disease prevalence does not seem to have changed significantly. Despite improved treatment and availability that have reduced the level of global malaria and HIV/AIDS, the prevalence of these infections are still worrisome. A number of reasons can account for this:

Firstly, the infrastructure at the hospitals in most African countries is very inadequate. There is a need to have more specialized services in all the hospitals. In Africa, physicians or general practitioners (G.P) seem to "diagnose and treat all ". Many G.Ps in Africa seems to be medical demagogues with a lot of inflexible medical assumptions rather than cooperative and collaborative medical care. This is partly due to the fact that few specialized doctors such as cardiologists, infectiologists, urologists etc exist. Health care provision is left in the hands of many ego centric health care practitioner rather than consultative health care practitioner.

From the foregoing, hospitals in Africa need to be created and with strengthening of specialized infectious diseases units that can operate on highly integrative care with health care built on solid scientific basis rather than on presumptive medicine. Since $70 \%$ of Africans populate in rural areas, health care centers in the rural areas need to be equipped and built on the principle of functional integrative health care services. This means that patients do not need to travel more than $120 \mathrm{~km}$ to receive basic treatment and perhaps specialized health care for infectious diseases.

Additionally, health literacy level in Africa has to improve; the patients and the different health care providers have to understand their rights and respect rather than any coercion or intimidation during health care provision. Perhaps, the lessons from the current Ebola outbreak can be taken on board to buttress these points. In initial period of the outbreak of Ebola, many to the patients as well as health care providers did not know it was Ebola. The suspicion that the child eat a fruit contaminated with Ebola virus by a fruit bat, and that the child was immediately taken to the traditional doctor at borders depicts a number of lessons to be considered in the control of infectious diseases. First lesson is that, rural Africans have to very inform or made literate on health issues, secondly, health care services have to be made available by governments within proximity and at affordable cost. Thirdly, the cultural knowledge and habits toward diseases have to be well studied and integrated in modern day African hospital setting. Fourthly, the traditional doctors across Africa have to be re-organized and studies on the best approach to integrate this into the conventional hospital carried out as well as creation of unique integrated health care centers that integrate certain elements of traditional practices would have to be considered now.

It is observed that $90 \%$ of Africans even when admitted in the conventional hospitals still consult traditional doctors concurrently. In 2013, Yongabi and his study group, working with more than 100 traditional doctors in the Boyo division discovered the need to objectively study the practices of traditional doctors with view toward synchronization into the main stream health care.

\section{Some Pitfalls in the Current Hospitals in Africa}

The African hospitals are proving inadequate to solve the heath of her people. What could be the reasons for this? First of all, if heath care in African hospitals mimics exactly the western approach, then it is bound to generate a lot of challenges continuously as is the case. The hospital set-up in Africa, though with western nomenclature, has to be adapted in an African context.

Perhaps, it would be worth taking a histo-medical exploration in the pre-colonial Africa to document succinctly how they conceived what was a disease, how they manage scourges even in the face of little success. What was a prototype health care practice in Africa in the pre colonial days? Certain examples come to mind and have been documented by Sofowora 1984. In certain villages in Africa, traditional birth attendants have organized cultural protocols 
with rudimentary tools on carrying out gynecological and pediatric care. Some had local ways of dealing with bone setting which is still widespread across Africa today.

Our premise in this paper is not to fail to acknowledge the setbacks of such a practice in modern medical arena, but to proclaim the importance to have studied these methods and improve upon with view to incorporating these practices and the practitioners into the modern hospital in Africa. With the increasing threats of diseases and with Medicare that does not seem to have a wide coverage across Africa, the need for WHO to revise the hospital setting in Africa inorder to incorporate its anthropology is critical.

History tells us that civilization started from Africa, yet Africa is at the very base of civilization today. This is partly because rather than building its culture and integrating with advanced western cultures, it seems that certain aspects of Africans are being replaced by different cultural perceptions. A Medicare that addresses the increasing health challenges in Africa is really needed previously published in a monograph in 2008 (Fig 2)

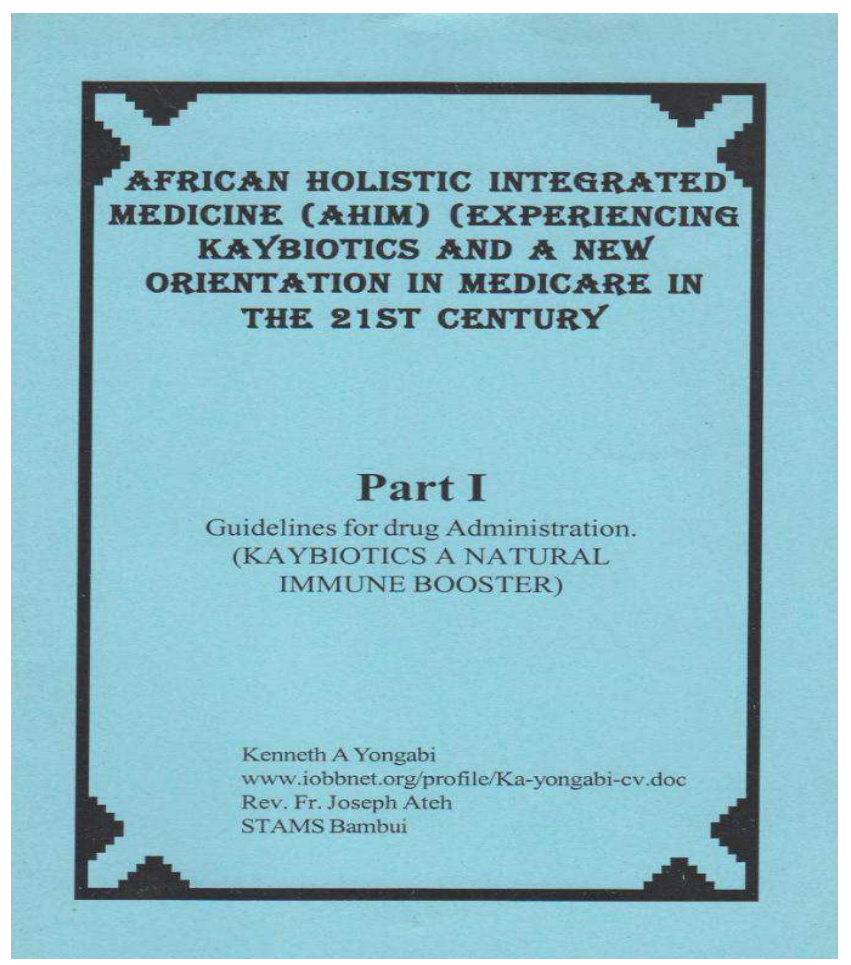

Fig. 2. Monograph: African Holistic Integrated health care model (Yongabi and Ateh, 2008)

The present Ebola outbreak in Africa has proven clearly that African hospitals have many challenges to deal with epidemics and would need a total over haul. As seen in fig 2 below, the level of animal human relationship in Africa is entirely different from that of the west. First, certain animals in African culture are used in rituals without any bother about disease risk. In many parts of sub Saharan Africa, people live in the same vicinity with animals and as well as predate on them.

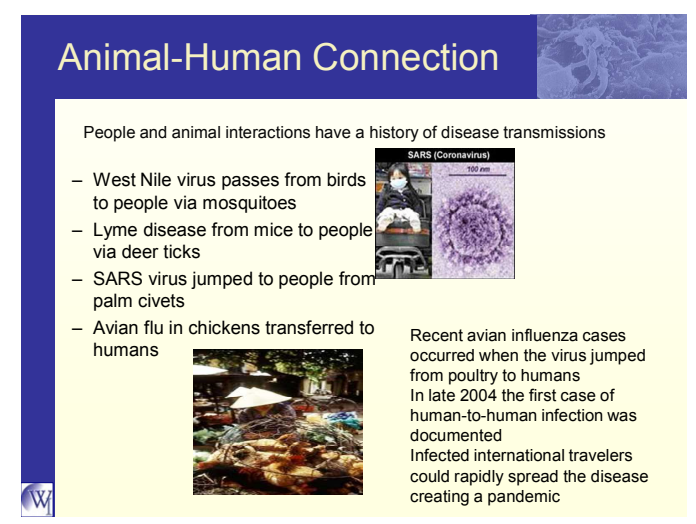

Fig. 3. Animal to Human Connection

Currently, changes in relationships between people and microbes are facilitating disease outbreaks in recent historical periods with changes in human behavior or circumstances as well mutations. Movement of pathogens as well changes in shared environments couple with domestication of animals have brought people and animals together. This increases risk of zoonotic disease transmission. Furthermore, Settlements brought people into close contact with accumulated wastes. These are critical points which the next generation of health care providers in Africa would have to address. In many poorer nations, many people suffer from infectious diseases of the poverty, while in affluent nations; an increasing number of people are afflicted with chronic diseases of the overfed. An estimated 2.8 billion people now live on less than \$2 per day with little access to health care. In Africa, infectious and parasitic diseases account for about $50 \%$ of all deaths, while in Europe they account for only $2 \%$. With this discrepancy, it would be theatrical to have a hospital in Africa that is exactly the same as a Western prototype. Poor countries do not have adequate financial resources and enough health care workers with profound understanding of the complexities of health care problems on the continent. Infectious diseases will continue to emerge and re-emerge, leading to unpredictable epidemics and difficult challenges to public health and science across Africa. Increase surveillance on a global scale to detect new disease outbreaks quickly is important. The healthcare system in Africa would need an upgrade in both human and financial resources. The application of anticipatory thinking and action to prepare for and avoid rapidly moving future pandemics is equally important.

Campaigns to eradicate serious illness among the world's poor with the development of better mechanisms to distribute drugs and vaccines and other pharmaceuticals to poverty stricken disease victims' needs serious attention. This will involve the need to create innovative ways to provide affordable drugs to victims in poor countries. Greater transparency by governments where disease outbreaks are likely to occur such Ebola needs to be encouraged. Economic liability issues arising from the rapid development of vaccines for swiftly moving diseases would have to be addressed with Provision of incentives for the development of new vaccines and medicines for endemic diseases in 
developing countries.

\section{The Ebola Outbreak of 2014 and Lessons for Developing an Ideal African Health Care}

The current outbreak of Ebola and its persistence has thought provoking lessons for African public health infectiologists. Let's look at the history, in 1976, in Congo, when the diseases was first noticed, Africans hadn't the the diagnostic tools to confirm if it was a viral infection, and more specifically Ebola. The usual African diagnosis then was one of cultural perception, that a mysterious diseases or spell was killing people. When the blood samples from infected people were sent to Belgium as Professor Peter Piot narrates, it was then they detected and named the Ebola virus $\mathrm{s}$ it is called today. What we see is a cultural perception to any disease in Africa and we also see lack of well equipped and decentralized hospitals across Africa for a long time. This is true on the premise that if the lessons from 1976 were built upon, then it would have been simple to diagnose the present infection that has caused this Ebola ravage that we are into at the moment.

Are African hospitals and doctors very equipped and aware of fevers? Its common prognosis in most hospitals to unconsciously consider fevers as malaria so most physicians in Africa generally prescribe an antipyretic with anti antimalaria as one stop therapy for fevers. Pyrexia of unknown origin still remains a big challenge to understand and tackle in African hospitals. For instance, there is HIV/AIDs induced PUO, malaria PUO, Typhoid PUO, Babesia induced PUO (Yongabi and Chia, 2014) and Ebola induced PUO. Algorithm for diagnosing fevers of unknown Origin is shown below but requires intense modifications to address future potential epidemics.

The case of Ebola clearly suggests great caution with the diagnosis and treatment of fevers of unknown origin. It may be another case of a new infectious diseases epidemic tomorrow presenting with pyrexia of unknown origin. Are medics in Africa prepared? For instance, what are the baseline temperatures for the various infectious diseases induced fevers? Perhaps a baseline inventory of temperatures for various tropical fevers needs to be carved out so that in the event of a sudden new epidermic, a better diagnosis could be quickly made. This has been very disturbing as in the every first case of infections; health care workers were unable to tell if it was Ebola. This has put many health care workers at risk with a number of hospital acquired viral infections. We now know the history Ebola and how it is transmitted as per the figures below; but there may be so much yet to be understood about this virus, and that can partly explain why the disease persists. The figures below provide a snap shot of what Ebola is all about.

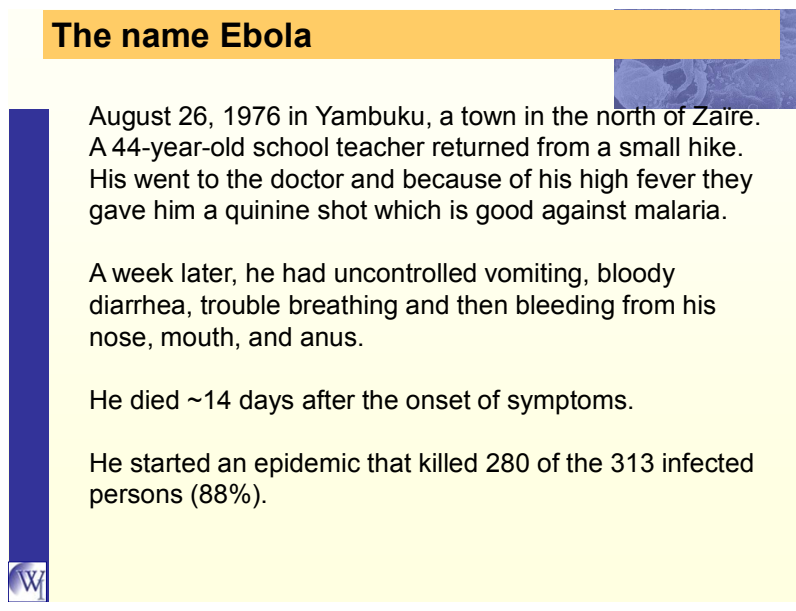

Fig. 4. Historical review of the name Ebola

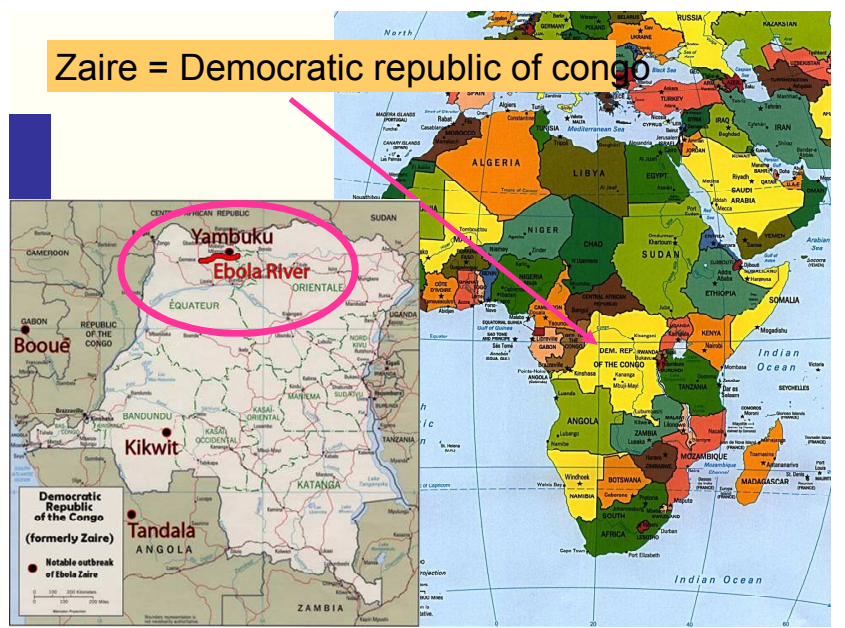

Fig. 5. The origin of Ebola virus

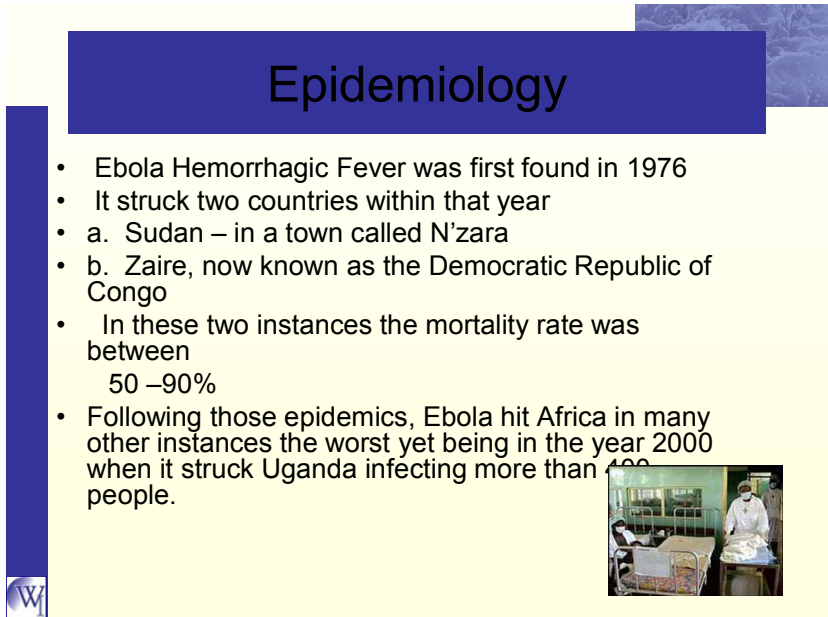

Fig. 6. Epidemiology of Ebola 


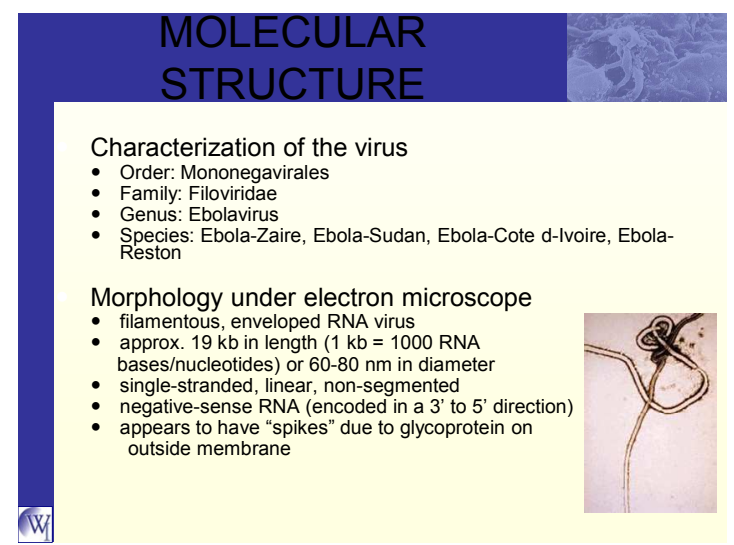

Fig. 7. Molecular structure of Ebola

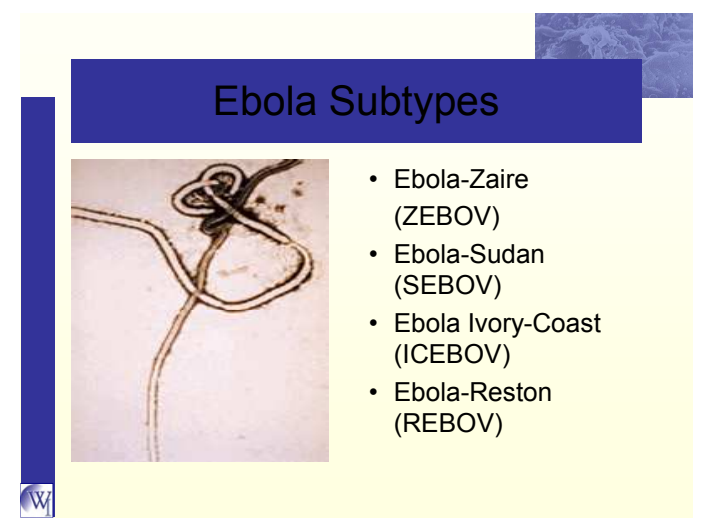

Fig. 8. Ebola subtypes

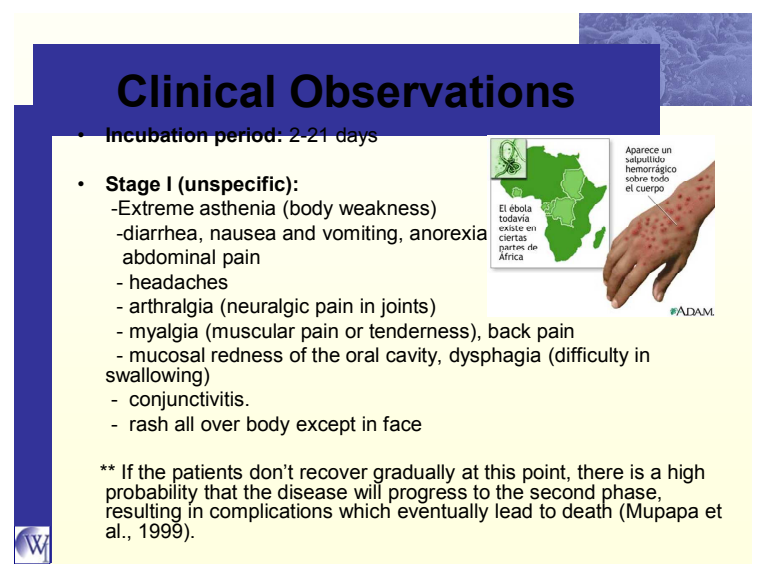

Fig. 9. Clinical observations with Ebola infection

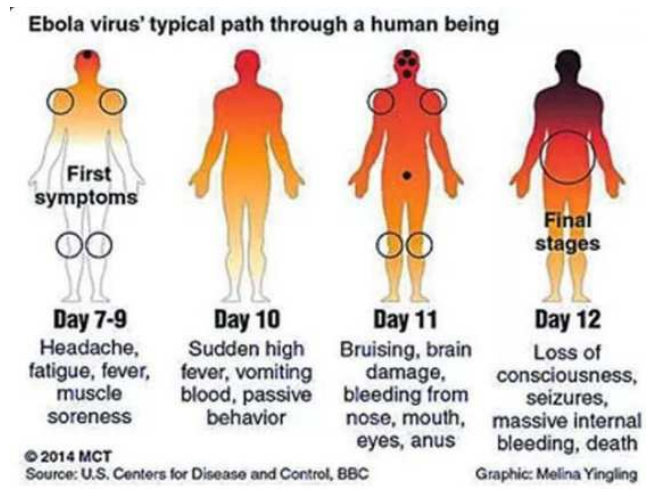

Fig. 9.1. Incubation period

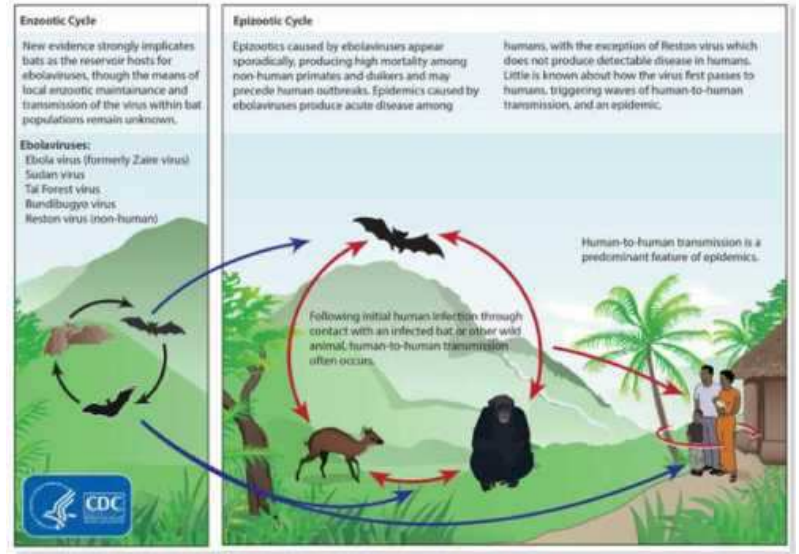

Fig. 10. Transmission pattern of Ebola

Professor Peter Piot in an interview on British Broadcasting Corporation (BBC) on December 23,2014 with a series of re-broadcasts resonated an opinion that we uphold, that the epidemic still has a "long tale" and far from being over. He may uphold also that there was an initial slow response to the Ebola containment but we would additionally advocate for a strong culture and African driven institutional framework to deal with emerging infectious diseases in the future. The reliance on foreign aid and doctors and as well as equipment has tremendously rolled back the Ebola spread across and within the affected countries but the need to build strong surveillance systems and stations, as well as infectious diseases units with decentralized health care services across the whole of Africa with particular focus on villages remain so critical for future diseases containment. More clinical innovations are needed in African hospitals as already mentioned. A cross section of some of the needs is to have more specialized infectious diseases clinics or centre at all hospitals across all hospitals in and health centre in Africa with rapid diagnostics tests and facilities. Comprehensive laboratory services with safety trainings and quality control and assurance should made available at these health centre. Suffice enough to comment that these in the long run are cheaper and would be cost effective and beneficial than having to deal with epidemics as is the case is.

Treatments of fevers and infections should be consultative and collaborative in hospitals. A team comprising of Specialist doctors e.g. infectiologist, general practitioners, Pharmacists, laboratory scientists and nurses should be members of a treatment team to discuss potential treatment and treatment outcomes of a case scenario. No one health care worker should be at a centre of a prescription decision monopoly, except in an extreme case where no co worker is available. An appropriate structure for the private health care systems would need to be figured out.

Quality control for services offered by all health care workers would have to under quality assurance from time to time with clearly outlined standard Operating procedures. In Africa, most of these quality assurance and control services are hardly enforced.

African hospitals where all medics work free from 
coercion and with mutual respect of qualification and colleagueship are critically needed. We also advocate an African hospital system where surgeries are not carried out by one general practitioner as the case often encountered today with causalities that no one is held responsible. Due to the cultural inclination of Africans with their beliefs, myths etc, a surgical team even at the most local hospital should comprise of: a surgeon if not a GP, Infectiologist/Physiologist, anesthetic, radiologist, Nurse, medical lab scientist, a priest or pastor and a theatre counselor and alternative and complementary medical practitioner.

Generally, in the face of Ebola fevers or treating infections at the hospital levels across Africa, antibiotics have to be thoroughly checked. The efficacy of most of the antiinfective is dwindling and most prescriptions are rather done on presumption without an antibiogram guide. For the case of an Ebola patient with wasting, hemorrhagia, vertigo, septicemia etc. Swift works up programs that combine swift and efficient as well as time bound diagnosis are needed. Forinstance, a fast IV line with the required electrolytes balance, appropriate antibiotics, vitamins complex etc are needed. Other specific considerations would have to be made if patients are diabetic especially with time at premium to make such decisions, state of the liver, kidneys etc .All these approaches would have to be reviewed and require clinical innovations. What kind of hygiene and wastes management is needed in an African hospital setting? The PRF holistic research clinics in some parts of Cameroon reflects some of the ideas for an Ideal African hospital prototype.

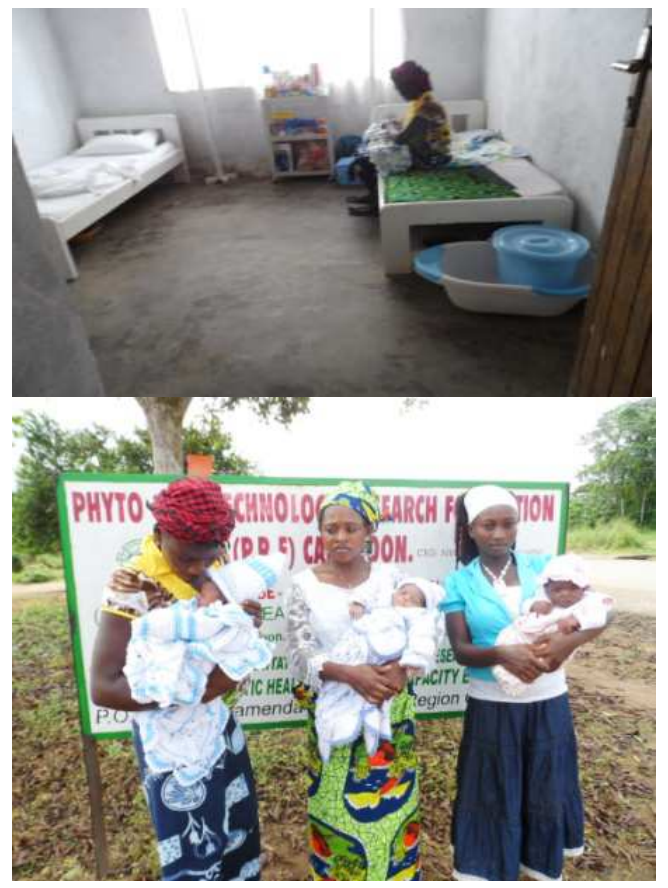

Fig. 11. PRF holistic research clinic in Mamfe-Cameroon

Preventing future epidemics in Africa requires a very proactive transdisciplinary approach. This means that the hospital structure would have wastes management as a very serious issue as per the figure below:

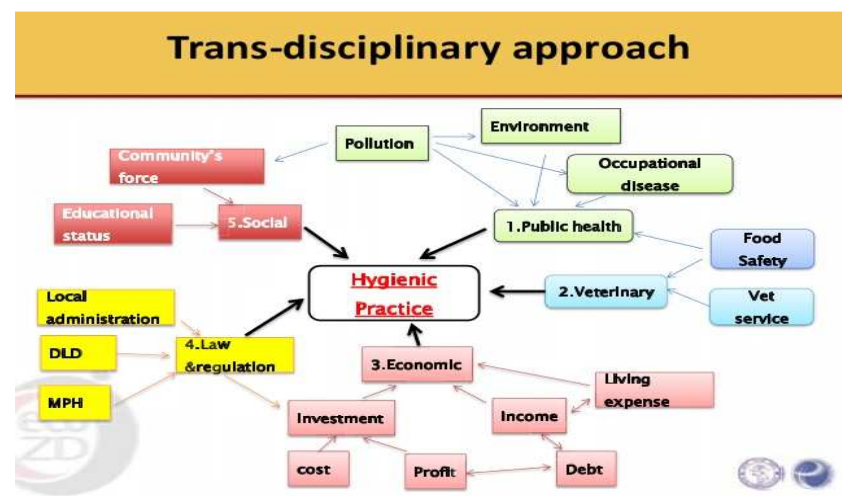

Fig. 12. Transdisciplinary Approach for intervention in Public Health

At the moment, hospital wastes disposal and hospital wastewater treatment during outbreaks such as the case of Ebola has to be seriously considered. Generally, wastewater treatment is not organized across most African health care centers. Wastewater treatment and possible recovery technologies are expensive and capital intensive. African health care centers can run small scale integrated anaerobic digesters to kill pathogens and use water use biocoagulant to recover water rather than expensive polyelectrolytes and quaternary ammonium compounds. The use of such technologies such as Phytodisinfectants in local hospitals for treating water and wastewater at low cost are studied by Fig

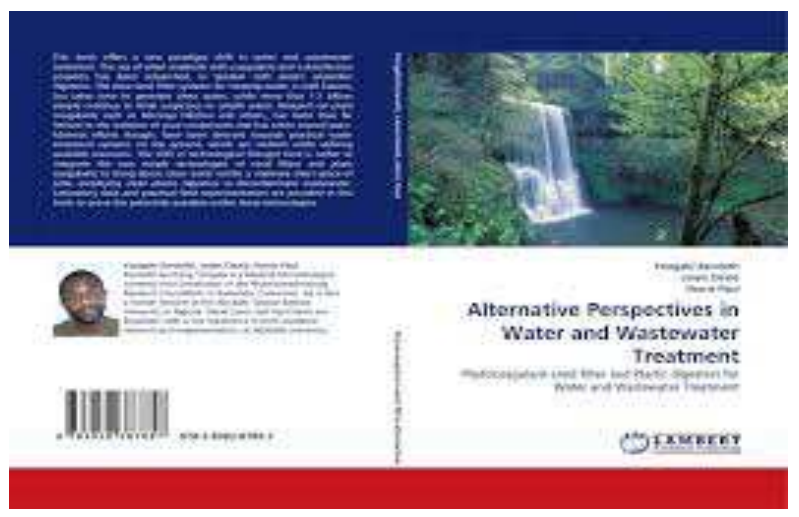

Fig. 13. Book Published by Yongabi 2010 using a range of local materials

Small scale digesters located at integrated health centers across Africa to disinfect pathogens from wastewater from hospital lavatories and intensive care units could be exploited

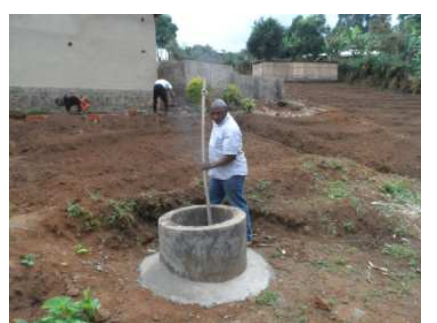

Plate 1. Small scale digesters at PRF experiment station, Cameroon

This can also be used to treat slaughter house wastewater that usually discharge blood mixed wastewater onto the environment thus disseminating pathogens widely. 


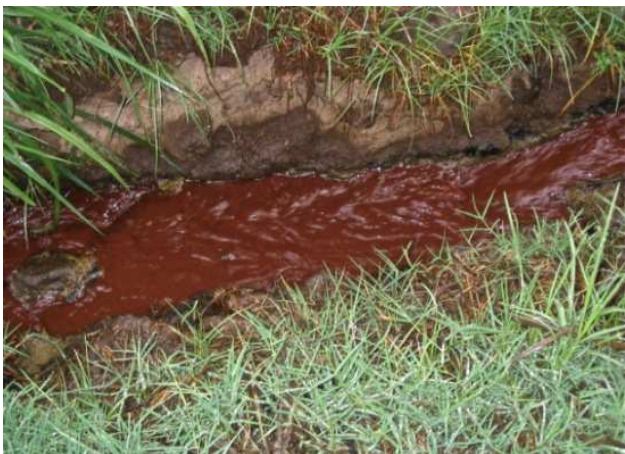

Plate 2. Animal slaughter house wastewate discharged directly on to the environment

In conclusion, the need to advocate an integrative approach to the diagnosis, treatment and management of Ebola hemorrhagic fever in Africa is needed. A radical clinical innovation to the diagnosis of fevers of unknown origin is a lesson to build on especially as Africa still remains the hub for future outbreaks. What kind of hospital and health care systems is needed for Africa that can address current endemics and prevent future epidemics? The current hospital systems need to be modified and adapted to the cultural heritage and traditional knowledge of Africa inorder to benefit sustained health care. These are recommendations that WHO can work on.

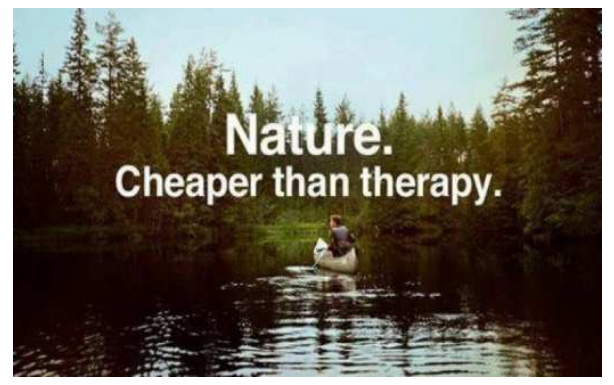

Plate 3. Therapeutic lessons from Nature

\section{References}

[1] K. A. Yongabi (1997) Natural Pharmacy a Treatment of Common Diseases uses herbs rum, Cameroon an Unpublished. PP 40.

[2] K. A. Yongabi, U. H. Dukku, M. O. Agho and I. Y. Chindo (2000) Studies on the Antifungal properties of Urtica dioica uritcaceae (Stinging Nettle). Journal of Phytomedicine and Therapeutics Vol.5. No1, PP 39-43.

[3] K. A. Yongabi, M. O. Agho, I. Y Chindo and M. W. Buba (2000) Evaluating the medicinal potentials of indigenous plants in controlling Microbial contamination of Poultry feed. Journal of phytomedicine and Therapeutics vol. 5, No 2, PP 98-102.

[4] Yongabi, K. A; Agho, M. O; Adamu, H.M Adebitan, S. A; Angeh, J. E and Jalo I. I. (2002) Antibacterial Effects of the extracts of Carica papaya, Urtica dioica, and Aloe barbadensis on some Bacterial Isolates from Lycopersicon esculentum mill (tomato) Journal of Chemical Society of
Nigeria, vol 27, No. 2, Pp 180-182

[5] I. Y. Chindo; K A Yongabi M. O. Agho; Z. B, Timothy and D.N, Anong (2002) Extracts of Ageratum conyzoides: Pesticidal Activity and phytochemical. Journal of Chemical Society of Nigeria, Vol.27, No 2.PP110-113

[6] Yongabi K. A. Yusuf, 1.2; Dongs, I. S; and Anong, D. S. (2004) Prevalence of Filariasis and some Traditional Methods of attending to the disease in wum North West Cameroon Nigerian Journal of Microbiology, Vol. 18, No I. In press.

[7] K.A. Yongabi (2004) Studies on the use of medicinal plants and Macro Fungi (Lower plants) in water and wastewater purification proceedings of an international $\mathrm{E}$ seminal organized by the International organization for Biotechnology and Bioengineering (10BB) Sweden, June 14-25 www. Biotech.kth.se/iobb/news/Kenneth/photos.

www.biotech.kth.se/iobb/news/kenneth04.doc,

[8] K. A. Yongabi (2003) A technical report on capacity building training of Rural women in some selected communities of Bauchi state on soap (washing) production. A technical report submitted to Development Exchange Centre (DEC), Bauchi office, March 17, 2003, FEPA/ZERI Centre, ATBU, Bauchi.

[9] K. A. Yongabi, P. L. Harris, A. S. Sambo and M. O. Agho (2003) Managing Cow Dung with a cheap, Low-tech Plastic Digester Proceedings of the 29 WEDC International Conferences on water and Environmental Sanitation coorganized by water Engineering Development Centre, and Loughbrough University, UK. In conjunction with the Ministry of water resources.

[10] Resources, Abuja holding at Abuja on September 22-26 PP486-489. Proceeding at wedc web page (2004) on line: $\mathrm{http}: / /$ wedc.(boro.ac.UK/conferences/pdfs/29/yongabi 1.pdf pp 74-77

[11] ATBU Bulletin. ZERI makes Discoveries vol.18 No 2 JanApril 2001 ISSN 0189-5850.

[12] M.O. Agho, K. A. Yongabi A. G. Ibrahim and A.S. Sambo. Ecological Management of Dermatophilosis in Ruminants using plant - based products (unpublished).

[13] K. A. Yongabi (2004) Assessment of the Efficacy of Extracts of Distemonantus benthamianus Baillar and Cucurbita pepo C on Microorganisms isolated from infected human semen. Unpublished MSC Thesis, ATBU, Bauchi.

[14] Yongabi, K. A., Agho, M.O., Gurama, A. U., Adamu, H.M (2000) Sensitivity of Tomato rot fungi to some plant extracts. A paper presented at the $34^{\text {th }}$ Annual Conference of the Agricultural Society of Nigeria $115^{\text {th }}-20^{\text {th }}$ October, Bauchi, Nigeria. www.songhai org-Porto novo, 2003.

[15] Horst W. Doelle (2004) Microbial Metabolism and Biotechnology. Proceedings of an E-seminar organized by the International organization for Biotechnology and Bioengineering (IOBB) www. Biotech.kth.se Electronic Journal of biotechnology http://www ejb.org/content.

[16] Jacky Foo (2000) Integrated Bio-systems: A global perspective. http://www.ias.unu.edu/proceedings/icibs/ibs/ibsnet/INFORM 2000-paper.htm IBS (integrated Biosystems) htt://www.ias unu.edu/proceeding/icibs/ibs/ibsnet Ecosan (Ecological Sanitation) newsletter http://www.gtz.de/ecosan/docs/NL Eng.pdf 
[17] Ahmed Hassan (2003) Effect of Sanitation system on ground water. Proceedings of the $29^{\text {th }}$ WEDC International Conference holding on the $26-29^{\text {th }}$ Sept., at Abuja, Nigeria PP 183-186.

[18] Coker, A.O., Sridhar, M.R.C. and Martins, E.A (2003) Management of Septic Sludge in southwest Nigeria Proceedings of the $29^{\text {th }}$ WEDC International Conference holding at Abuja Nigeria, 26-29 ${ }^{\text {th }}$ September PP 315-317.

[19] Mohammed Dauda and Osita O.O (2003) Solid Wastes management and re-use in Maiduguri Proceedings of the $29^{\text {th }}$ WEDC International Conference holding at Abuja on the 26$29^{\text {th }}$ September PP 98-106.

[20] S. Balasenthil; S. Arivazhagan; C.R. Ramachandian V. Ramachandian; and S. Naginic (1999) Chemo preventive potential of Neem (Azodirachta indicia on 7, 12-d, methylbenz (a) anthracene (DMBA) induced hamster buccal pouch carcinogenesis. Journal of Ethnopharmacology 67: 189195.

[21] H. M. Kim., M. J. Kim., E. Li., Y.S. Lyu., C.Y. Hwang and N. H. An. (1999) The Nitric Oxide-Producing properties of Solanum incanum. Journal of Ethnopharmacology 67: 163169

[22] Geoffrey C. Kirby (1996) Medicinal plants and the control of parasites. Medicinal plants and the control of protozoa disease, with particular reference to malaria Transactions of the Royal society of Tropical Medicine and Hygiene 90:605-609

[23] Cox, P. A., Balick, M. J., (1994) The Ethno botanical approach to drug Discovery scientific American 270: 60-65.

[24] Adetumbi. M. A., Javer, G.T. and Lau, B. H (1986) Inhibition of in vitro Germination and Spherulation of Coccidiodes immitis by Allium Sativum. Current Microbiology 13: 73-76

[25] Lambo, J. A. (1979) The healing power of herb with special reference to obstetrics and gynecology. In: African Medicinal plants ed.sofowora, E.A. University of Ife press, Nigeria pp 23-31.

[26] Aurora Fernander-Astroga., Maria Jose Hijarrubia., Aoria Hernander., Ines Arana and Estersunen (1995) Disinfectant tolerance and antibiotic resistance in psychrotrophic Gramnegative bacteria Isolated from vegetables 20: 308-311.

[27] Ratsimamga, R. (1980) $3^{\text {rd }}$ OAU/STRC Symposium on Traditional Pharmacopeia and African medicinal plant, OAU/STRC, Lagos.

[28] Farnsworth, N. Rand Kaas, C. J. (1981) an approach Utilizing Information from Traditional Medicine to identify tumor inhibiting plants: Journal of Ethnopharmacology 31: 85-100.

[29] Sofowora, E. A. (1982) Medicinal Plants and Traditional Medicine in Africa Wiley, New York.

[30] Kenneth Yongabi, Lisa Avery and Ambar Pertiwiningrum (2013) A Commentary of Occupational Infectious Diseases due to Agricultural Practices in Sub- Saharan Africa, Biomass and

Bioenergy www.sciencedirect.com/science/article/pii/S09619534140012 51

[31] Oyawoye, O.O, Salawu, S.J, Yongabi, K.A, Salawu, N.O and Omole, F.O (2006) Antibiogram pattern of Bacteria associated with Septic wound infection at Specialist Hospital Bauchi. Paper in press in the PeCop Journal of Tropical medicine and Health 